\title{
$>$ A imagem da morte: arte contemporânea e produção de sentidos
}

> The image of death: contemporary art and production of meanings

\section{por Vinícius Borges Figueiredo}

Doutorando em Artes Visuais pela PPGAV (Programa de pós-graduação Artes Visuais), pela UFRGS (Universidade Federal do Rio Grande do Sul). E-mail: viniciusfigueiredo.arte@gmail.com. ORCID: 0000-0001-6340-6559.

\section{Resumo}

Mediante as relações de sentido que possam existir entre as temáticas do corpo, representação e morte, sobretudo nas produções que se utilizam do suporte da fotografia, e também pensando no ponto de mudança entre o documento fotográfico para a mestiçagem da arte contemporânea, o presente artigo se propõe refletir sobre a produção de três artistas visuais: Rosângela Rennó, Christian Boltanski e Ydessa Hendeles. Os referidos artistas se utilizaram de práticas mestiças e do suporte fotográfico em suas produções visuais, de modo que, através de um olhar mais aprofundado sobre suas obras, seja possível identificar parcialmente a forma como estabeleceram um diálogo entre a representação do corpo morto e a arte contemporânea.

Palavras-chave: Fotografia. Memória. Arte Contemporânea. Produção de sentido.

\begin{abstract}
Through the relations of meaning that may exist between the themes of the body, representation and death, especially in the productions that use the support of photography, and also thinking about the point of change between the photographic document for the miscegenation of contemporary art, this article aims to reflect on the production of three visual artists: Rosângela Rennó, Christian Boltanski and Ydessa Hendeles. These artists used mestizo practices and photographic support in their visual productions, so that, through a more in-depth look at their works, it is possible to partially identify how they established a dialogue between the representation of the dead body and art contemporary.
\end{abstract}

Keywords: Photography. Memory. Contemporary art. Production of meaning. 


\section{A fotografia e seu vínculo com o real}

Se pensarmos que o ciclo da vida está diretamente ligado à morte, a fotografia, enquanto representação de algo ou de alguém, pode assumir o papel de fóssil ou permitir uma experiência de vida que existe apenas no continuum das imagens e de sua produção de sentido. Nessa sequência, o fóssil também sofre com a ação do tempo, assim como nosso corpo envelhecido, que perde o brilho e cede à duração do tempo, a foto também apaga, morre. E o que poderia restar dessa morte? Se a natureza segue um ciclo que nos permite continuar, a foto seria nosso vestígio e a arte contemporânea o mecanismo que permitiria a transposição desse ciclo, a partir do momento que questiona a representação da vida (ou a ausência dela) pelas poéticas visuais de seus artistas.

A história da fotografia foi marcada por transformações tecnológicas desde sua gênese - em que se problematizou e expandiu a interface entre arte e ciência. A necessidade de se criarem formas de representação da realidade com mais eficiência e rapidez foi uma das principais preocupações da comunidade científica no final do século XIX. Nesse período, em diversos lugares do mundo, vários processos de fixação de imagens foram desenvolvidos. Os franceses Joseph Nicéphore Niepce (1765-1833) e Louis Jacques Mandé Daguerre (1787-1851) foram alguns dos inventores reconhecidos como precursores da fotografia. Além de impulsionar o desenvolvimento tecnológico da ciência, a invenção da fotografia mudou totalmente a forma de percebermos a arte. A fotografia extrai suas impressões do mundo sem a necessidade do fazer artesanal - do desenhista ou pintor. Na imagem que se quer representar, não existe mais o intermédio de 
um pincel, e sim de um aparelho. Mas essa imagem que se forma não surge magicamente, mas requer uma intervenção humana muito mais complexa.

A fotografia, atualmente, ainda é considerada traço do real, prova indubitável da presença de vida, como defendiam alguns autores, a exemplo de Roland Barthes. No entanto, podemos sugerir que ela eterniza a morte para os vivos, assim como faz a sepultura para os mortos. Segundo Barthes, em vez de apenas polemizar a fotografia em seu contexto econômico e social, por conta de sua reprodutibilidade técnica, é necessário situá-la em seu vínculo antropológico com a morte: “[...] É preciso que a Morte, em uma sociedade, esteja em algum lugar; se não está mais (ou está menos) no religioso, deve estar em outra parte: talvez nessa imagem que produz a morte ao querer conservar a vida"1.

O surgimento da fotografia, nas primeiras décadas do século XIX, foi útil para as indústrias emergentes que se beneficiaram do uso da imagem impressa. Do mesmo modo, contemplou uma parcela da sociedade que, anteriormente, em busca prestígio social, recorria aos pintores retratistas.

A História da fotografia foi marcada por transformações tecnológicas desde sua gênese, tendo expandido a interface entre arte e ciência. Além disso, sua popularização nas sociedades ocidentais do século XIX engendrou debates nos meios artísticos e intelectuais acerca do estigma de realidade na produção estética. A superfície de aparente realidade da fotografia fez dela um modelo de mimese para artistas e acadêmicos que, a princípio, entendia a criação partindo

\footnotetext{
${ }^{1}$ Roland Barthes, A câmara clara: notas sobre fotografia, 1984, p. 137-138.
} 
da fiel reprodução da natureza e não da transformação desta através de um processo mental.

A problemática do estigma da fotografia em relação à realidade só pode ser resolvida a partir do esclarecimento de uma questão: a relação entre imagem fotográfica e o sujeito representado. No primeiro capítulo de $O$ ato fotográfico, Philippe Dubois trata da verossimilhança do índice; para o autor, o efeito do real que a foto produz se deve à sua semelhança com o objeto retratado. ${ }^{2}$ Ele constata, entretanto, que a fotografia, ainda que como testemunha da existência do referente (aquele que foi fotografado), não significa que se pareça com ele; a relação da imagem fotográfica com seu referente, ou com o real, pode ser lida, portanto, sob três aspectos: (1) como espelho do real (o discurso da mimese) ou imitação da natureza, em que há semelhança entre a fotografia e o mundo real que foi fotografado; (2) como transformação do real (o discurso do código e da desconstrução), em que há alteração da imagem do referente de acordo com a mudança de enquadramento, cortes, cores, transformando, assim, a realidade; e (3) como índice, quando o retorno ao referente é eminente. Dubois ressalta que a fotografia não pode ser tomada como reflexo exato de um tempo, ou fato, já que ela sofre a transmutação da interpretação e da subjetividade do olhar. Outro autor que trata da questão do referente é Roland Barthes. Em A câmara clara ${ }^{3}$, ele diferencia o referente da fotografia dos outros sistemas de representação encontrados na arte, não como algo facultativamente real, mas como prova da existência de um corpo ou coisa real que esteve presente diante do fotógrafo.

\footnotetext{
${ }^{2}$ Philippe Dubois, $O$ ato fotográfico, 2001.

${ }^{3}$ Roland Barthes, Op. Cit., 1984.
} 
Nesse sentido, não é possível negar que algo ou alguém esteve realmente (no passado).

A fotografia pode criar um conflito entre dois termos distintos: o real e o vivo. Quando analisamos os trabalhos de artistas contemporâneos que se utilizaram de práticas mestiças ${ }^{4}$ e do suporte fotográfico em suas produções visuais, sem conhecermos a história daquelas fotografias, ou excluindo o uso de fotografias de corpos ou mortuárias, não podemos determinar se o sujeito retratado está vivo ou morto. No entanto, podemos atestar a sua existência sobre a forma poética da própria materialidade da fotografia. Ao transpormos, contudo, o sentido de real para o passado, o que toda foto sugere é um sentimento de "isso foi", expressão que Barthes traduz como "o noema da fotografia"; em outros termos: o que vejo encontrou-se lá, em espaço e tempo distintos.

Toda fotografia é um certificado de presença. Flusser ressalta o caráter mágico das imagens técnicas e fala do papel da imaginação como mediação entre o homem e sua interpretação do mundo. ${ }^{5} \mathrm{O}$ pensador critica também a alienação

\footnotetext{
${ }^{4}$ No texto introdutório da obra Mestiçagens na Arte Contemporânea, intitulado "Poiéticas e poéticas da mestiçagem", Icleia Cattani inicia a delimitação do conceito de mestiçagem, explicitando como o termo foi deslocado de outras agendas acadêmicas para o campo da arte contemporânea, na intenção de retirá-lo de suas conotações pejorativas e evidenciar sua potência para a produção artística contemporânea. "[...] de misturas de elementos distintos que não perdem suas especificidades." (Icleia Borsa Cattani, "Mestiçagens na arte contemporânea: conceito e desdobramentos", 2007, p. 11). No artigo Os lugares da mestiçagem na arte contemporânea, Cattani menciona que essa mistura de diversos elementos constitutivos, presentes na obra de forma simultânea, não se anulam e nem se fundem, permanecendo "[...] sempre presentes, numa relação tensa, ambivalente, contraditória" (Icleia Borsa Cattani, "Os lugares da mestiçagem na arte contemporânea", 2004, p. 67).

${ }^{5}$ Vilém Flusser, Filosofia da Caixa Preta, 1985.
} 
perante as fotografias que surgiram como forma de auxiliar as pessoas em diversos setores de produção de conhecimento.

O que observamos, no entanto, é que, ao longo do tempo, as pessoas passaram a viver segundo suas representações fotográficas. Flusser, na obra acima referida, antecipou questões sobre a produção e divulgação de imagens que vivemos na contemporaneidade. Podemos pensar nas relações entre realidade e imaginário apoiados na expressão "caixa preta". No campo da eletrônica, por exemplo, essa denominação serve para designar a parte complexa de um circuito eletrônico, que é intencionalmente escondida pelo design de um circuito maior e substituído por uma caixa vazia, que leva apenas o nome do circuito omitido.

O termo usado por Flusser é uma metáfora que remete à ideia de magia e mistério. Ele reivindica que, além da fotografia como matéria ou produto final, deveria haver uma filosofia para o que ocorre na parte obscura da máquina. Artistas como Rosângela Rennó, Christian Boltanski e Ydessa Hendeles utilizam o imaginário da morte como criação de paradigmas que investigam o que é velado e o que pode ser revelado através da fotografia e produções que delas se envolvem.

Algumas técnicas incorporadas à fotografia tentavam driblar seu traço de real, tão defendido em sua natureza histórica. Isso pôde ser visto nos idos do final do século XIX, quando os pictorialistas ${ }^{6}$ entravam em contraposição sobre o

\footnotetext{
${ }^{6} \mathrm{O}$ movimento pictorialista eclodiu na França, na Inglaterra e nos Estados Unidos a partir da década de 1890, congregando os fotógrafos que ambicionavam produzir aquilo que consideravam como fotografia artística, capaz de conferir aos seus praticantes o mesmo prestígio e respeito granjeado pelos praticantes dos processos artísticos convencionais. O problema é que
} 
estatuto da fotografia enquanto obra de arte, rebuscando-a aos moldes da pintura clássica em prol de uma legitimidade artística.

Segundo Philippe Dubois, a fotografia pertenceria à ordem do índice, uma operação fisioquímica, que se dava a partir de um referente real, transposto para sua natureza bidimensional. Mesmo não comportando esse espaço real, a foto traria em si um traço de realidade, assumindo para o autor ora o lado icônico ora o simbólico. ${ }^{7}$ Ao longo de seu texto, ele ressalta não apenas a aura icônica da fotografia, mas também põe em pauta as várias relações de troca que estão em confluência dentro do estudo da imagem.

A concepção da fotografia como representação fidedigna da realidade fazia parte do espectro racional e positivista que moldou o pensamento hegemônico do século XIX, reforçado pelo surgimento das tecnologias de captação de imagens e dispositivos ópticos, que foram acolhidas com bastante euforia nos meios científicos e artísticos da época. Seu uso era justificado pela crença da objetividade e neutralidade das provas visuais. No entanto, esse conceito de "realidade" atribuído à fotografia pouco a pouco mudou seu paradigma com menor enfoque na superfície do registro visual e maior interesse em compreender a relação das imagens coletadas no contexto cultural de cada sociedade onde certos códigos eram inscritos. Dessa maneira, podemos pensar

essa ânsia de reconhecimento levou muito dos adeptos do pictorialismo a simplesmente tentar imitar a aparência e o acabamento de pinturas, gravuras e desenhos ao invés de tentarem explorar os novos campos estéticos oferecidos pela fotografia (Itaú Cultural, "Pictorialismo", 2005).

${ }^{7}$ Phipippe Dubois, O ato fotográfico, 2001. 
que, além de documentar e registrar, a fotografia passou a produzir narrativas tencionando ainda mais as relações entre "documento de registro" e história.

\section{A questão da modernidade}

André Rouillé destaca que durante o período de desenvolvimento da sociedade industrial ocorreu um conjunto de transformações políticas, sociais e tecnológicas, que ofereceram condições propícias à criação da fotografia. Ao mesmo tempo, ela cumpria o papel da objetividade dos processos de industrialização, se transformando no principal paradigma da modernidade. ${ }^{8}$

Com o surgimento do daguerreótipo, aqueles que criticavam o modernismo lamentaram que a imagem gerada não necessitasse mais da habilidade manual da pintura, enquanto modernistas viam a mecanização como forma de conferir agilidade aos processos de representação. Enquanto a fotografia reproduz todo o visível, visto ou não visto, sem seleção e sem perda, o desenhista representa apenas um aspecto restrito: o que ele consegue perceber. Assim, a maneira fotográfica de ver e de fazer as coisas do mundo contrapõe-se à tradição artística.

Além do desenvolvimento tecnológico, a invenção da fotografia mudou totalmente a nossa percepção do mundo, pois ela extrai suas impressões não por intermédio de um pincel, mas de um aparelho que cria uma imagem muito mais complexa. A fotografia surgiu do cruzamento do conhecimento de dois

\footnotetext{
${ }^{8}$ André Rouillé, A fotografia: entre documento e arte contemporânea, 2001.
} 
dispositivos seculares: de um lado, a câmara escura e, do outro, a sensibilidade à luz de certas substâncias.

$\mathrm{Na}$ antiguidade, a relação entre arte e tecnologia se dava pela diferença entre tékne (pintura, escultura, artesanato) e mousiké (poesia, música, que era considerada uma categoria superior). No entanto, conforme a modernidade alargava seus passos, os críticos e os próprios artistas se distanciaram dessas categorias. Se, por um lado, Baudelaire rejeitava a fotografia como categoria da arte, Benjamin acreditava que a mesma é a razão da ruina da pintura.

A industrialização do Ocidente deslocou a produção de bens materiais dos setores primários (trabalho manual das matérias primas) para os secundários (atividades mecânicas da transformação). Num processo parecido, a fotografia introduziu a quantidade, o número e a medida na própria matéria da imagem. A fotografia como expressão de um conceito de arte é apresentada por Rouillè (2009) como uma mudança estética que se desenvolveu ao longo da história para além das questões relacionadas ao índice e ao documento de registro. Aos poucos, os fotógrafos passaram a desconstruir a forma da fotografia, dada também a sua inserção em outros campos, com o da moda e o da publicidade. Estes contribuíram para uma ideia de que a imagem opera tanto para fazer a coisa quanto para representá-la, sendo, ao mesmo tempo, receptiva e ativa, como pode ser também construção de um olhar ou reverberação de sentido. É nessa esfera que os artistas fotógrafos ou não fotógrafos, mas que se utilizam da fotografia como meio de expressão, conseguiram ultrapassar o ponto de vista ontológico da foto e a realidade em proveito das alianças e das mesclas. 
O fotógrafo e documentarista suíço-americano Robert Frank (1924-2019) fez parte dessa geração de fotógrafos que se utilizou da fotografia enquanto regime de expressão. Através de enquadramentos intempestivos, os acordos da estética clássica foram rompidos para dar lugar a imagens dissonantes: corpos deslocados, cenas tremidas, apagamentos, borrões - a granulação, as deformações, os desfocados - no centro de seu regime formal. Frank libera a fotografia não só do documento, mas de suas regras. Se as fotos de Frank rompem com a estética documental é porque elas não representam, mas apresentam, assim como o trabalho do artista francês Christian Boltanski que, em sua pesquisa, reposiciona a questão do retrato do acervo familiar. Ambos, mesmo com trabalhos, objetivos e períodos distintos, questionam a imodéstia de verdade da fotografia-documento, e propõem a rejeição do sujeito-fotógrafo ao instante decisivo, a redução do real às aparências. A imagem fotográfica não é um corte temporal nem o rastro direto e automático de um real preexistente. Ao contrário, ela é antes de tudo, a produção de um novo real.

A fotografia durante a modernidade ajudou a redefinir a forma como a sociedade relacionava as práticas do "ver" com a memória e a lembrança. Segundo Halbwachs, a memória pessoal remete a um grupo; o indivíduo carrega a lembrança, mas está sempre em interação com a sociedade. Daí construirmos as nossas lembranças individuais na tessitura das memórias dos diferentes grupos com os quais nos relacionamos. ${ }^{9}$

A fotografia torna possível, no presente, a realização de entusiasmo e, apesar de figurar a ausência de um tempo, de um passado, projeta o indivíduo

\footnotetext{
${ }^{9}$ Maurice Halbwachs, A memória coletiva, 1990.
} 
para esse mesmo tempo. A memória possui uma estreita relação com a fotografia, que registra e documenta imagens. A sepultura eterniza a morte para os vivos, assim como a imagem representa a vida, ao figurar a ausência. A foto é sempre um vestígio que completa uma imagem mental, o que torna nossa memória feita de fotografias. Daí a importância para este trabalho de pensar a relação entre a fotografia e a morte, e como essa ligação perdura até a contemporaneidade.

\section{A fotografia e seu vínculo com a morte}

Antes mesmo da invenção da fotografia no século XIX, a morte já se apresentava em diversos rituais e objetos que elaboravam esteticamente o luto. Os homens das cavernas usavam os crânios de ancestrais, bonecos ou efígies que representavam o corpo, entre outros artefatos. As máscaras mortuárias romanas, por exemplo, eram usadas como moldes de gesso ou argila sobre a face do morto, na tentativa de retratar fidedignamente a estrutura física do rosto de um ente querido falecido. O presente artigo destaca no que se refere a esses moldes, uma forma de se preservar um vestígio. Com a fotografia, proporcionavam-se novas condições do ver e de se criar uma imagem, sentido em que a imanência opera como uma espécie de mediação da fotografia entre aqueles que vivem e aqueles que já se foram.

Historicamente, o nascimento da fotografia foi acompanhado pela prática da fotografia mortuária, que consiste em retratar os mortos com o auxilio da câmara escura. Com o passar dos anos, o uso da máscara mortuária deu espaço para a fotografia nos ritos de preservação da imagem dos mortos por sua 
característica de verossimilhança, reprodutibilidade. Naquele período, o retrato pós-morte foi bastante difundido, principalmente pelas classes mais abastadas. Da Alta Idade Média até meados do século XIX, a relação do homem com a morte se transformou drasticamente, o que passou a ser percebido nas suas de representações.

Segundo Belting, a fotografia abarcava uma convergência de sentimentos de mudança diante do inevitável momento da morte e foi requisitada como antídoto para essa crise. ${ }^{10}$ A memória do morto ora traz uma relação com a perda de algo querido ora produz uma reflexão no limiar entre o vazio e a lembrança, os espaços por preencher, uma imagem familiar, o retorno do morto que apaga e rememora. Assim, a fotografia era utilizada como forma de driblar a própria morte ou como forma de vivenciar o luto. Era como se o desparecimento da matéria abandonasse o vestígio fotográfico, o traço e prova de existência que resgatavam socialmente o morto.

É interessante ressaltar o fato de que todos que são fotografados vão morrer, se já não morreram. De todos os ritos de passagem, do batizado ao casamento, a morte é seguramente o mais difícil de lidar, pois se projeta intensamente num aspecto pessoal e melancólico. As imagens da morte, assim, nunca são esquecidas, e exercem um fascínio impressionante, seja no cinema, no fotojornalismo ou na publicidade. São várias as formas como essas imagens nos chegam. O presente artigo não se propõe a ser um estudo sobre rituais de fotografia mortuária, tampouco vem para falar da história da morte na fotografia, mas tem como objetivo colocar em diálogo as diferentes visões de morte na arte

\footnotetext{
${ }^{10}$ Hans Belting, Por uma antropologia da imagem, 2005.
} 
contemporânea, através de um breve recorte da obra dos artistas Christian Boltanski, Rosangela Rennó e Ydessa Hendeles, pensando como é construído o sentido de suas produções, além dos significados convencionalmente associados à morte.

\section{Diferentes visualidades da morte em Cristian Boltanski}

O artista Christian Boltanski articula fotografias de anônimos com lembranças pessoais. É um minucioso trabalho de reconstituição que virtualiza as narrativas de seu imaginário, levando o espectador a relacionar a obra de Boltanski, no que tange à memória, família, luto e à finitude humana, à própria história. Boltanski trabalha com a ideia de memória individual e coletiva. A memória individual se realiza na perspectiva do outro, ou melhor, no emaranhado de lembranças do grupo social ao qual o indivíduo pertence, com suas características socioculturais específicas. Sendo assim, as lembranças individuais se alimentam das mais variadas memórias de um grupo, gerando um sentimento de pertencimento ou memória coletiva, o que se passa no campo simbólico. A obra fotográfica chamada Faces, de 1996 - em papel transparente com três fotografias costuradas em destaque -, apresenta sete personagens femininas em um momento de aparente descontração [Figura1]. Dentre elas, as expressões de três mulheres se sobrepõem à imagem das outras, numa espécie de recorte que salta o plano da imagem maior, focando, sobretudo o olhar. 


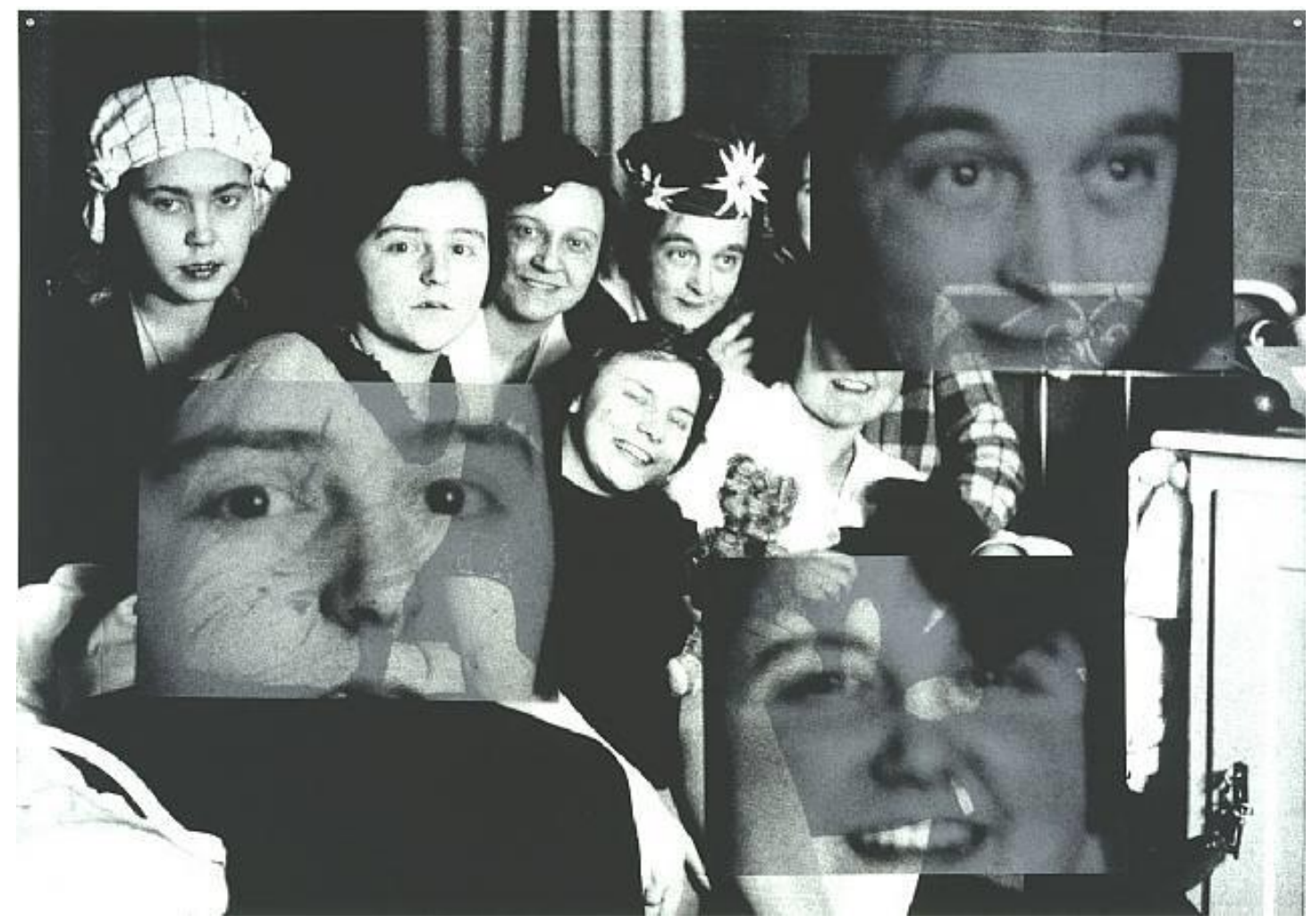

Figura 1

Christian Boltanski, Faces, 1996, Fotografia em papel transparente com 3 fotografias adesivas, 85 x $122 \mathrm{~cm}$. Galerie Bernd Klüser, Munich, Munique, Alemanha.

A fotografia, mesmo quando usada como documento, não representa o real e não precisa tentar recriá-lo. Ao contrário, a fotografia, enquanto discurso, com seus meios próprios, faz existir a produção de sentido que fabrica o mundo. Enquanto Barthes, com a ontologia fotográfica, vai da coisa à imagem, o procedimento anti-representativo dos artistas, como no caso da obra de Boltanski, tenta não anular as imagens em função dos seus referentes, reconhecendo a autonomia das fotografias, que são, assim, algo novo que se desprende do referente. Nesse sentido, podemos pensar na dimensão da distância e da ausência. A mesma distância que o artista destaca em suas 
personagens evoca um distanciamento, inerente a toda fotografia, de seu referencial enquanto vestígio da vida. A obra Faces remonta à história não cronológica de uma sociedade que prega o imediato determinado por certos questionamentos: quem eram essas mulheres? Haveria um parentesco entre elas? Qual a importância do recorte de seus olhares entre tantos outros na mesma foto?

Isso colocaria a morte como atestado de efemeridade do mundo, pois suas personagens podem tanto ser elementos da composição como representar uma família ou grupo social. Contudo os olhares em destaque evidenciam o caráter desse objeto artístico, pelo seu poder de instigar ao olhar mais ingênuo, o desejo da descoberta de uma história inacessível, como o destaca Susan Sontag: "As fotos mostram as pessoas incontestavelmente presentes num lugar e numa época específica de sua vida; agrupam pessoas e coisas que, um instante depois, dispersaram-se, mudaram, seguiram o curso de seus destinos independentes"11.

A capacidade de recordar, a retenção de impressões está ligada à ideia de que não há nada de único na memória. Ela é um objeto imaginado no passado que adquire a carga emotiva da crença. Em sua obra, Boltanski não encara a imagem apenas como prova de um tempo que já passou. Presença, ausência e apagamentos são peças entrecruzadas, mas seu trabalho trata de um tempo que está sendo construído a cada olhar presente. O retrato não é a cópia ou simulacro de um modelo de realidade preexistente à imagem, mas a atualização fotográfica de algo que aconteceu. Isso reposiciona a fotografia do domínio dos fatos para o das atualizações, e do registro para as trocas simbólicas, e, assim, a arte

\footnotetext{
${ }^{11}$ Susan Sontag, Diante da dor dos outros, 2003, p. 85.
} 
contemporânea proporciona esses campos de convergência. Nossa lembrança nos prega truques e a noção de interpretação de uma fotografia ou de um fato associado a ela não necessariamente obedece a uma realidade categórica, mas faz parte da construção de uma lembrança que é tomada como nossa. Cada membro familiar constrói seu próprio repertório imagético afetivo. E ao nos debruçarmos sobre um álbum de fotografias, nós nos permitimos não apenas voltar ao passado como também a lugares que se formam no presente [Figura 2].

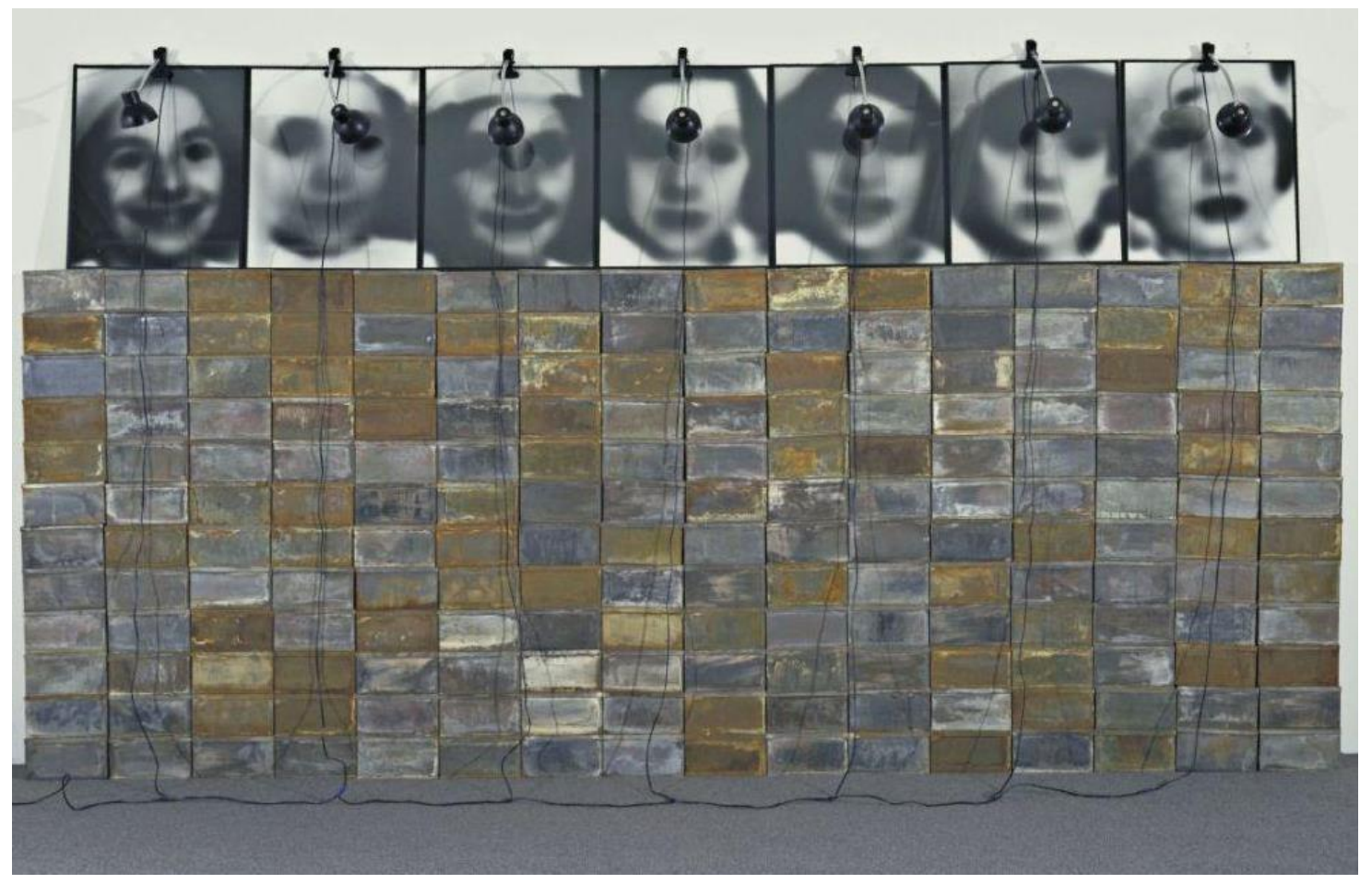

Figura 2

Christian Boltanski, The Storehouse, 1988, Impressões em papel gelatina de prata, lâmpadas elétricas e caixas de estanho contendo fragmentos de tecido, $211.2 \times 375.8 \times 21.6 \mathrm{~cm}$. MoMA Manhattan, NYC. 
Christian Boltanski cria objetos de desejo e de culto e suas imagens remetem a uma religiosidade fora do sentido de lugar comum. Assim, virtualiza uma árvore genealógica imaginária que nos une numa mesma família e nos aproxima daquilo que encaminha todo homem para morte, não só física, mas como morte da própria imagem. $\mathrm{O}$ artista usa a foto como um meio que direciona todos ao mesmo fim. Sua obra não se encerra em si mesma, mas desconstrói, como objeto transformado pelo mundo, seus mitos e ficções em detrimento de sua poética.

\section{Rosângela Rennó: a imagem do morto e a morte do vestígio}

A morte transforma nosso corpo, assim como acontece com a fotografia envelhecida. Na obra do Boltanski, como na de outros artistas, todo questionamento de morte é sempre pautado pela imagem conservada de um momento em que as pessoas vivenciaram alguma situação. Mas o que ocorre quando a imagem registrada se trata do próprio corpo morto de um individuo? A série intitulada Atentado ao Poder, de 1992, realizada pela artista Rosângela Rennó, convoca a essa provocação. O trabalho é composto por 15 fotografias em preto e branco, em papel resinado (fotos apropriadas de jornais), acrílico, parafusos e duas lâmpadas fluorescentes. A montagem da obra é acompanhada por um texto em adesivo aplicado sobre parede, The Earth Summit, que pode ser traduzido como "Na cúpula sobre a terra." Sobre a obra de Rennó, duas questões podem ser primordialmente destacadas. Primeiro com relação à imagem do corpo morto e depois o deslocamento dessa imagem para o espaço de arte; antes 
de focar na imagem da artista, é necessário pontuar como a fotografia trabalhava a imagem do morto nos primórdios de sua existência.

A fotografia mortuária surgiu praticamente com a invenção da fotografia, no século XIX, e uma característica marcante dessa prática é que, mesmo usada em contexto de luto, apresentava um caráter de espetáculo em sua composição estética; muitas vezes eram idealizadas, com referências de temas clássicos da pintura. Isso com intenção de manter viva a memória de entes queridos ou destacar sua imagem de bom cristão, ou ainda contribuir no processo de construção da memória de familiares. A fotografia mortuária se distancia nitidamente das imagens dos mortos propostas por Rennó. No trabalho da artista, percebe-se a apropriação: prática comum à arte contemporânea, que consiste em deslocar imagens ou objetos de seu contexto de origem e função para a obra ou espaço de arte. Um traço marcante da obra de Rennó, que compartilha da ideia da vida em um mundo saturado por imagens, não havendo muito sentido em produzir uma nova imagem, a não ser dentro de seu processo de criação poética. A artista, assim, coleta tais imagens de jornais, doações, dentre outras formas e as reposiciona em seu trabalho artístico.

Atentado ao Poder é uma série que trata de um diferente tipo de espetacularização da morte. Suas personagens são anônimas e vítimas desse anonimato [Figura 3]. Trata-se de imagens recolhidas das páginas policiais que noticiam as chacinas que vitimizam a população negra das favelas do Rio de Janeiro. Além de não possuírem identificação, suas identidades são diluídas pela massificação da problemática social em questão: a violência nas ruas do Rio de Janeiro. Rosângela Rennó coloca as imagens selecionadas - inicialmente 
publicadas no sentido horizontal pelos jornais - na vertical. Esses corpos em suspensão foram re-situados frente à violência e à crueldade a que foram submetidos. Mas existe outro sentido além do apagamento social das vítimas, que é o movimento oposto proposto por Rancière, o do dissenso: a estética do dissenso constitui-se pelo desacordo. Para Rancière, as práticas estéticas são caracterizadas pelo sistema das formas que determinam a experimentação, e as práticas políticas como qualquer prática social. Para ele, a estética é um regime específico de identificação e do pensamento dos sistemas das artes. ${ }^{12}$

No regime das imagens, as próprias perdem seu conteúdo: o modo como, na obra de Rennó, a alteridade é colocada em xeque pelas relações de diferença, do dissenso. Assim, uma imagem pode se colocar como uma alteração, uma variação desse regime dominante, que se situa em dois polos: a relação simples que produz a semelhança de um original, (A imagem do morto) onde a imagem se suprime como objeto de contemplação e realiza operações, e o jogo de operações entre o visível e o dizível, que tende a opor a sua presença visível a qualquer operação e a qualquer sentido, produzindo a arte diante da alteração da semelhança. As imagens mostradas pela artista desencadeiam um processo mental muito mais pungente do que a superfície de sua representação; Rancière tenta resumir dizendo que a imagem é uma categoria da "partilha do sensível"13. Ela pertence (essa ideia) à estruturação do senso comum, no seio do qual nós vemos, falamos, pensamos e agimos. Esse senso comum se dá no modo de apresentação das coisas aos sentidos, e os modos de interpretação que dão sentido a esses modos de apresentação. Assim, o trabalho de Rennó, ao deslocar

\footnotetext{
${ }^{12}$ Jacques Rancière, 0 destino das imagens, 2012.

${ }^{13}$ Ibidem, p. 7.
} 
as imagens da morte para o espaço do museu torna visível a estética dos invisíveis socialmente.

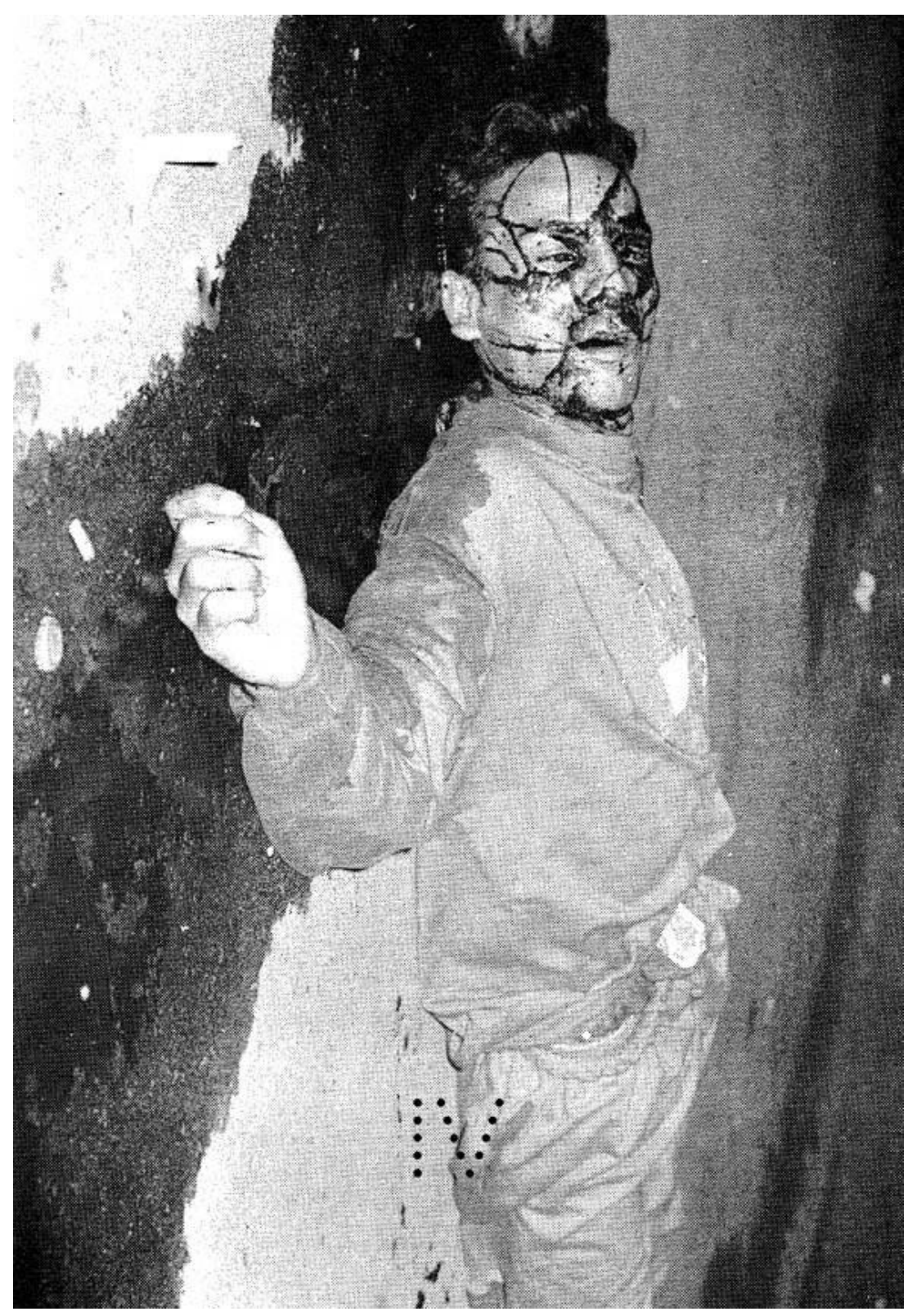

\section{Figura 3}

Rosângela Rennó, Atentado ao Poder, 1992, foto quatro, 15 fotografias p\&b em papel resinado (fotos apropriadas de jornais), acrílico, parafusos e 2 lâmpadas fluorescentes, texto em adesivo aplicado sobre parede (The Earth Summit), $320 \times 25 \times 25 \mathrm{~cm}$. Acervo pessoal da artista. 
Rancière busca questionar o senso comum dominante, procurando, pelas fissuras, outras formas de senso comum, que se poderia dizer "dissensuais", a partir da convergência do sensível e do seu sentido. ${ }^{14} \mathrm{O}$ dissenso está no centro daquilo que chamamos arte. Em sua definição "estética", a arte define-se pelo encontro de duas capacidades. Primeiramente, uma technê, que resulta de uma operação que produz objetos e performances. Mas também uma capacidade de "dissenso", de recolocar em questão certo estatuto do senso comum (um modo dominante de apresentação das coisas). É nessa esfera que se instaura o trabalho de Rosângela Rennó, a ideia de uma imagem contra a imagem, de uma descontinuidade em relação ao regime dominante, segundo o qual as formas sensíveis produzem afetos, envolvem interpretações e ativismo político. Através do dissenso, ver alguma coisa como arte significa ver duas coisas de uma vez só: é um problema de relações entre superfície de exposição das formas e superfície de inscrição das palavras.

O teor político desse trabalho faz um jogo de memória: um lembrar para esquecer que punge o espectador com algo que ele gostaria de evitar. Ao fazer isso, Rennó agrega às imagens dessas mortes uma nova memória que confronta, de forma perturbadora, a fragilidade não só do nosso corpo, mas de nossa própria imagem enquanto vestígio social e humano. $\mathrm{O}$ apagamento proposto por ela ao mesmo tempo torna sensível e visível ao nosso olhar a observação de um corpo sem vida que também é imagem, linguagem e história. A possibilidade de leituras faz da morte uma personagem, deixando em segundo plano o cenário do crime,

\footnotetext{
${ }^{14}$ Jacques Rancière, O destino das imagens, 2012.
} 
dada a importância da verticalidade dessas imagens ao nos confrontarem e observarem.

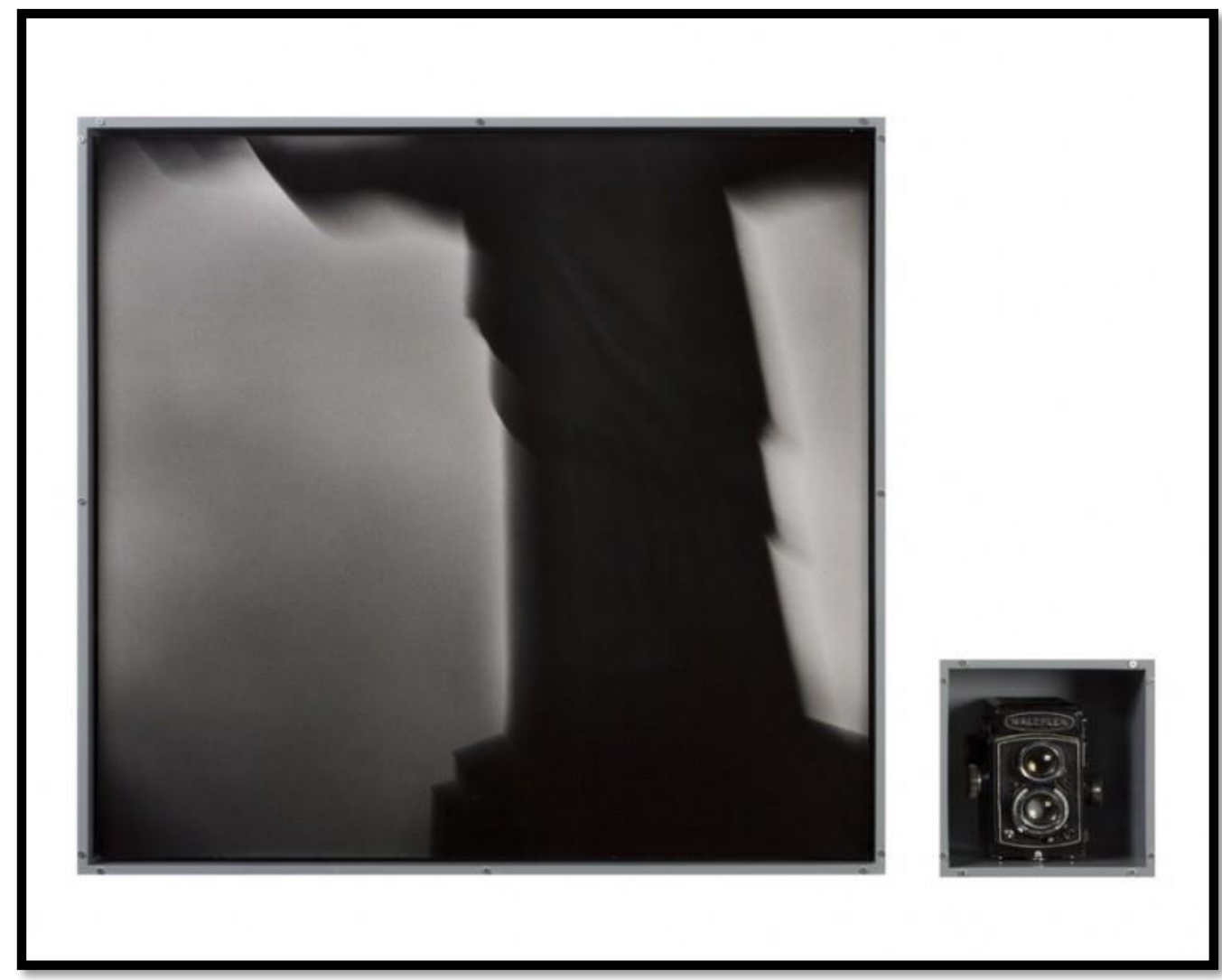

Figura 4

Rosângela Rennó/ Iuri Frigoletto, A última foto, 2006, Walz Flex Fotografia em papel de prata/gelatina e câmera fotográfica Walz Flex I emolduradas (díptico) Dim.: foto 67,8 x 67,8 x $12,4 \mathrm{~cm} /$ câmera 19,7 x 17,8 x 12,4 cm. Acervo pessoal da artista.

Por se tratar possivelmente de um último registro dessas pessoas, trago, para contraponto dessa obra, outro trabalho da artista intitulado $\mathrm{A}$ última foto [Figura 4]. Nesse trabalho, Rennó convida vários artistas para realizar retratos da estátua do Cristo Redentor, do Rio de Janeiro. Municiados de câmeras analógicas antigas, as fotos produzidas por eles foram montadas lado a lado de suas 
respectivas câmeras, que eram lacradas cada qual com sua fotografia de origem. Essa atitude radical e irônica da artista potencializa as discussões sobre a morte da imagem, ou a morte do objeto representado.

\section{Ydessa Hendeles: Colecionismo e fantasmagoria}

Ydessa Hendeles é filha única de judeus polacos sobreviventes de Auschwitz. Nasceu em 1948, em Marburg, na Alemanha; e cresceu no Canadá. The Teddy Bear Project é uma instalação concebida pela artista-curadora que apresenta mais de três mil fotografias em preto e branco que incluem a presença do Teddy Bear, um ursinho de pelúcia que foi inventado em 1903 e nomeado para Teddy Roosevelt.

As imagens que Hendeles coletou para elaborar a sua instalação foram em grande parte compradas no eBay entre 1999 e 2001, extraídas de coleções pessoais e álbuns de família e são classificadas em grupos de acordo com assunto, postura, cenário e vários outros critérios taxionômicos. Isso inclui categorias tão inesperadas quanto equipes femininas de basquete do início do século $\mathrm{XX}$, posando com ursinhos de pelúcia, festas de casamento com ursinhos de pelúcia, mulheres nuas com ursinhos de pelúcia, soldados com ursinhos de pelúcia, retratos de cães sentados com ursinhos de pelúcia, e assim por diante.

Em 2002, Hendeles, realiza a exposição Partners (The Teddy Bear Project) exibida pela primeira vez na exposição coletiva Same Difference na Ydessa Hendeles Art Foundation, em Toronto. Para realizar a instalação, a artista e curadora apresenta o trabalho combinado, que dialoga no mesmo espaço com 
obras adquiridas de artistas como Diane Arbus, Maurizio Cattelan, James Coleman, Hanne Darboven, Walker Evans, Luciano Fabro, On Kawara, Paul McCarthy, Bruce Nauman, Giulio Paolini, Jeff Wall e Lawrence Weiner.

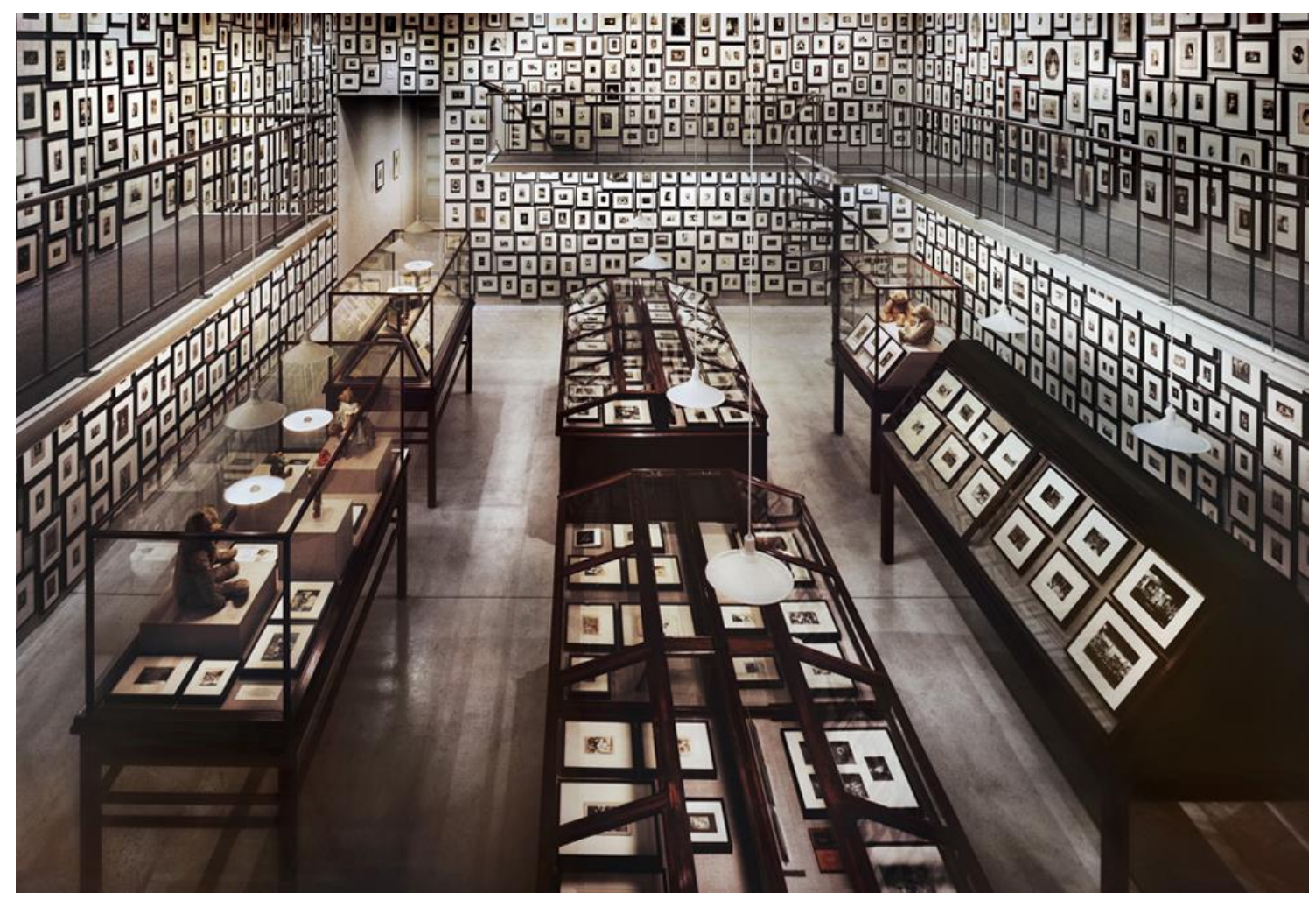

Figura 5

Ydessa Hendeles, (The Teddy Bear Project), 2002; installation view, Haus der Kunst, Munich; variable installation dimensions; 3000 family album.

A produção de sentido desse projeto apresenta uma dualidade introduzida pelo brinquedo e as próprias vidas que se perderam durante a Segunda Guerra Mundial. O urso é emblemático e sua apresentação associada a uma estética do acúmulo e da sobreposição quase que claustrofóbica dessas imagens estabelece uma relação complexa de parceria entre o conforto de uma infância perdida e o 
"efeito de Holocausto" através das imagens e de seus personagens em grande parte anônimos.

A forma que as lembranças se formam é composta por espaços vazios ou lacunas do esquecimento. Ao pensar em um diálogo entre os fragmentos presentes na memória e os segmentos vazios desta, Ydessa Hendeles, através de sua arte nos propõe um mundo de colecionismo, memória, repetição e acumulação.

O sentido claustrofóbico da experiência visual de um espaço com milhares de fotografias muda radicalmente para outro contendo apenas um objeto. A obra Him- de Maurizio Cattelan, de 2001 é uma escultura hiper-realista de Adolf Hitler de joelhos. Foi adquirida para compor a instalação - é fantasmagórica e sua postura penitente remete mais uma vez ao holocausto e a contraposição com as imagens da sala anterior.

A memória negocia com o registro e com os acontecimentos do passado, o que devemos reter ou que podemos apagar. Esse jogo opera de forma não linear e é no presente que se realizam as lembranças. Nelas se formam imagens mentais que organizam a ordem das coisas vividas no passado, como se houvesse em nosso cérebro um grande mosaico com peças ainda por preencher. Para cada lembrança a ser retida, é feita uma imagem para esse mosaico, cumprindo o papel dessas peças de preencher lacunas. À medida que não precisamos mais dessas lembranças, elas são apagadas ou sobrepostas por outras peças. Como uma remontagem da instalação The Teddy Bear Project em outro espaço ou outro lugar pode criar novas produções de sentido. 
De certa forma, Ydessa reprograma a ideia de museu e colecionismo em detrimento de sua busca poética, a montagem das suas imagens quase como um tecido que se sobrepõe em toda a parede, mesmo que milimetricamente enquadradas, acabam por fazer o que Hans Belting chama de as imagens que fogem ao enquadramento. Belting, sobre o fim da história da arte, destaca que a pós-modernidade se configura pela perda do enquadramento, uma narrativa que recorta o objeto. Segundo o autor, a história da arte até os anos 1960 propunha uma função de enquadrar certas imagens diante certos contextos e narrativas, quase sempre a partir de um olhar eurocentrista. ${ }^{15}$ Contudo, Belting não está falando da extinção do enquadramento (pois isso é impossível, considerando que é a situação a qual se insere qualquer sujeito). O que ele quer dizer com o fim da história da arte seria mais para o fim de um paradigma de enquadramento, pois o que se nega é a continuidade das antigas regras, que construíram certa história de estilos. A mesma negação histórica ocorre na proposta de coleção de Hendeles, que escolhe apenas pessoas posando com ursos e de um período muito especifico antes da Segunda Guerra Mundial. Assim como Belting, a artista sugere se pensar em uma história das imagens como um argumento que considera os significados sociais, políticos, religiosos e culturais.

\section{Considerações finais}

Foram muitos os sentidos da morte abordados por esses três artistas e cada nova leitura de seus trabalhos se abre para sentidos outros. Explorar a

\footnotetext{
${ }^{15}$ Hans Belting, O fim da história da arte: uma revisão dez anos depois, 2006.
} 
representação da morte em um trabalho de artes visuais é tentar buscar no passado o que dá sentido ao presente, quebrando com a ideia romântica de nostalgia. O retrato não é a cópia ou simulacro de um rosto-coisa-modelo supostamente preexistente à imagem, mas a atualização fotográfica de um rostoacontecimento. Dessa maneira, paradigmas da representação são contestados: de um lado, destroem a noção de modelo, pois a fotografia produz uma imagem no decorrer de um processo que coloca a coisa em contato; por outro lado, isso transfere a fotografia do domínio das realizações para o das atualizações das trocas simbólicas e dos diálogos. As imagens se inserem ao mesmo tempo no instante já passado e são atualizadas no contexto presente. Sua aparição e seu desaparecimento carregam o toque de poder ressuscitar simbolicamente os mortos.

A representação do corpo morto através da fotografia em relação à pintura e ao desenho está não no resultado, porém na sua gênese. A alegoria fotográfica é a expressão de ideias através de imagens: é uma figura estética, ao mesmo tempo efeito e motor da secularização da arte. Instaura-se, a partir da atualização, uma arte social e crítica do local da morte nos dias de hoje. Como observa Zigmund Bauman:

[...] A modernidade não aboliu a morte, somos tão mortais atualmente quanto o éramos no início da era da ordem humana. Ela, porém, trouxe enormes avanços na arte de repelir toda e qualquer causa de morte e impedir que tais causas ocorram. No entanto, o preço da desconstrução é a vida policiada do princípio ao fim pelas guarnições ubíquas do inimigo banido. Tornamo-nos de fato, inválidos acompanhando a vida das janelas de um hospital ${ }^{16}$.

${ }^{16}$ Zigmund Baumand, Modernidade Líquida, 2001, p. 194. 
O artista contemporâneo, que tem como suporte a fotografia, instaura em sua obra uma reflexão significativa sobre a morte. Segundo Barthes, toda fotografia remete a uma ideia de morte. ${ }^{17} \mathrm{O}$ artista que se apropria de imagens pessoais ou anônimas gera uma temporalidade diferente para antigas e novas identidades, assim como nos ritos de família, casamento, cenas do cotidiano, funerais etc. A morte, que era antes ritualizada, como nas fotografias mortuárias, nos dias de hoje é negada por um ideal de representação que visa à saúde e à vida plena, embora se morra do mesmo modo como se morria antes. A diferença se encontra no fim ou nas transformações que sofreram certos rituais, e talvez resida nessa negação, a imagem da morte hoje.

\section{Referências}

BARTHES, Roland. A câmara clara: nota sobre fotografia. Rio de Janeiro: Nova Fronteira, 1984.

BAUMMAN, Zigmund. Modernidade líquida. Rio de Janeiro: Jorge Zahar, 2001.

BELTING, Hans. O fim da história da arte: uma revisão dez anos depois. São Paulo: Cosac Naify, 2006.

BELTING, Hans. Antropologia da imagem. Lisboa: KKYM + EAUM , 2014.

${ }^{17}$ Roland Barthes, Op. Cit. 1984. 
BELTING, Hans. Por uma antropologia da imagem. Concinnitas, Rio de Janeiro, ano 6, v. 1, n. 8, jul. 2005. Disponível em: http://www.fnac.pt/Antropologia-daImagem-HansBelting/a802003. Acesso em: 10 abr. 2020.

CATTANI, Icleia Borsa. Os lugares da mestiçagem na arte contemporânea. In: FARIAS, Agnaldo. Icleia Cattani. Rio de Janeiro: FUNARTE, 2004.

CATTANI, Icleia Borsa. Mestiçagens na arte contemporânea: conceito e desdobramentos. In: CATTANI, Icleia Borsa (Org.). Mestiçagens na arte contemporânea. Porto Alegre: Editora da UFRGS, 2007.

DUBOIS, Philippe. O ato fotográfico. Campinas, SP: Editora Papirus, 2001. FLUSSER, Vilém. Filosofia da caixa preta. São Paulo: Hucitec, 1985.

HALBWACHS, Maurice. A memória coletiva. São Paulo: Vértice, 1990.

ITAÚ CULTURAL. Pictorialismo. Disponível em: http://www.itaucultural.org.br/aplicExternas/enciclopedia_ic/index.cfm?fuse action=termos_texto\&cd_verbete $=3890 \& c d \_i d i o m a=28555 \& c d$ item $=8$. Acesso em: 10 abr. 2020.

RANCIÈRE, Jacques. O destino das imagens. Rio de Janeiro: Contraponto, 2012.

RENNÓ, Rosangela. Rosângela Rennó. Disponível em: http://www.rosangelarenno.com.br/. Acesso em: 10 abr. 2020.

ROUILLÉ, André. A fotografia: entre documento e arte contemporânea. São Paulo: 
SENAC Editora, 2009.

SONTAG, Susan. Diante da dor dos outros. São Paulo: Companhia das Letras, 2003.

\section{Referência para citação deste artigo}

FIGUEIREDO, Vinícius Borges. A imagem da morte: arte contemporânea e produção de sentidos. Revista PHILIA | Filosofia, Literatura \& Arte, Porto Alegre, volume 2, número 1, p. 533 - 562, junho de 2020. 